\title{
Forms of Further Corporate Education in the Slovakian Construction Industry
}

\author{
Marta Matulcikova ${ }^{1}$ \\ Anna Hamranova ${ }^{2}$ (ID \\ Daniela Brevenikovas ${ }^{3}$ (D) \\ Juraj Misun ${ }^{4}$ (D)
}

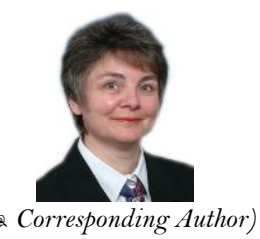

${ }_{1,2}^{12 .}$ Faculty of Business Management, University of Economics in Bratislava, Slovakia.

Email: marta.matulcikova@euba.sk

${ }^{s}$ University of Economics in Bratislava, Slovakia.

\begin{abstract}
The paper deals with further professional education, which involves educational activities aimed at improving knowledge, skills and abilities related to work performance. The focus is on selected attributes of preparing and implementing further professional education in construction companies in Slovakia. The research model was designed to detect weaknesses in assessing educational needs and the kinds and forms of education, to help improve the future organization of further professional education. The authors determined research assumptions and research hypotheses, conducted a questionnaire survey, and analyzed the statistical significance of the results using statistical tests and coefficients. There is minimal use of special-purpose methods for assessing educational needs; qualification education prevails in companies that most frequently provide adaptation education and introductory training. Statistically significant differences in the approach to further education were found based on level of completed education, job position, and company size. In further professional education that requires a guided form of education, distance education (either offline or online) is suitable for construction companies.
\end{abstract}

Keywords: Construction company, Digitization, Distance education, Educational needs, Form of education, Further education, Lifelong learning, Work performance, Work performance, Slovakia.

Citation | Marta Matulcikova; Anna Hamranova; Daniela Brevenikova; Juraj Misun (2021). Forms of Further Corporate Education in the Slovakian Construction Industry. Journal of Education and e-Learning Research, 8(2): 249-263.

History:

Received: 15 March 2021

Revised: 17 June 202

Accepted: 7 July 2021

Published: 26 July 2021

Licensed: This work is licensed under a Creative Commons Attribution 3.0 License $\frac{(\mathrm{ccc}) \mathbf{E}}{\mathrm{E}}$

Publisher:Asian Online Journal Publishing Group
Acknowledgement: All authors contributed to the conception and design of the study.

Funding: The research paper is funded by the nationwide research project scheme VEGA (Scientific Grant Agency of the Ministry of Education, Science, Research and Sports of the Slovak Republic and the Slovak Academy of Sciences (SAV))No. 1/0328/21: 'Post-pandemic Business Management: identification of temporary and sustainable changes in sequential and parallel identification of temporary and sustainable changes in sequential and parallel management functions in the context of the COVID-19 pandemic,' Faculty of
Business Management, University of Economics in Bratislava, Slovak Republic; Project coordinator: doc. Ing. JurajMišún, PhD.

Competing Interests: The authors declare that they have no conflict of interests.

Transparency: The authors confirm that the manuscript is an honest, accurate, and transparent account of the study was reported; that no vital features of the study have been omitted; and that any discrepancies from the features of the study have been omits
study as planned have been explained.

Ethical: This study follows all ethical practices during writing.

\section{Contents}

1. Introduction

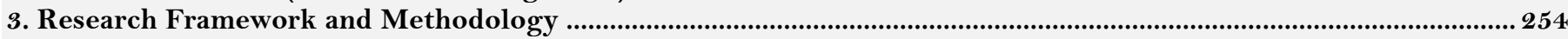

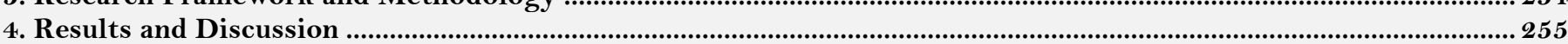

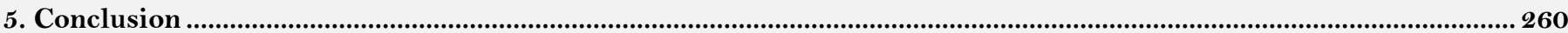

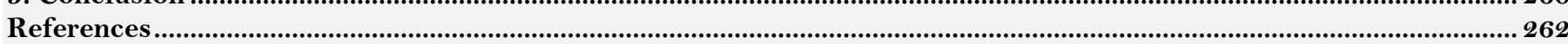




\section{Contribution of this paper to the literature}

The paper analyzes different kinds of further professional education in terms of qualification and re-training education, in the context of guided forms of education and the forms of education defined according to the number of participants. The paper emphasizes the necessity of an efficient preparation of further corporate education and training in the form of the identification of educational needs and the application of adequate methods of data collection. The research model designed by the authors for the conditions of the construction industry is generally applicable to all industries.

\section{Introduction}

Nowadays, as society becomes increasingly knowledge-based, high demands are placed on people. If individuals want to assert themselves, they must meet new, challenging requirements and develop their knowledge, skills and abilities in order to cope with the ever-increasing competition. This increases the importance of lifelong learning, which includes all the activities adults carry out during their lives to improve their knowledge, skills and competences.

Lifelong learning also includes further professional training, the process through which individuals acquire systems of knowledge and transform them into practice, or improve in the performance of their professional activities through the acquisition of new skills and habits (Park, Lee, \& Dabelko-Schoeny, 2016; Schoultz, Ohman, \& Quennerstedt, 2020; The Oxford Handbook of Lifelong Learning, 2011). The concept of Lifelong Learning (LLL) has both been described as a 'fashionable mantra, a political slogan', and as an active tool for stimulating economic growth and fostering social cohesion. LLL is implemented in diverse contexts, both in formal and informal settings(Panitsides \& Talbot, 2016).

Organizations can benefit from transitioning to a learning organization. Nowadays, the learning organization is viewed as the highest level in the evolution of organizational culture. The basic principles of this type of organization include features such as a collective mindset of employee learning, continuous improvement of employee skills, the provision of support for employees, and the rise of dynamic new models of thinking and achieving the required results. While certain factors, such as teamwork, leadership, information sharing, and innovation have a positive impact on organizations, poor communication or alack of activity on the part of managers and employees, on the other hand, have a negative impact. Zubr, Mohelská, \& Sokolová, (2017) argue that the learning organization model enables organizations to achieve competitive advantages; thus, the transition to a learning organization can help an organization improve their performance(Zubr, Mohelská, \& Sokolová, 2017).

According to the Labour Code in force in Slovakia, the following educational needs arise:

- On the part of the individual - the worker for whom an educational gap a rise. Individuals must develop their subjective abilities in order to perform their work in accordance with the required objective needs of the job, or to ensure the development of the employee's personality.

- As a result of changes in working conditions influenced by internal and external factors, which are often accompanied by innovative needs and manifest through changes in technical, technological, material conditions of work performance, etc.

- In the context of requirements for periodic examination and competence renewal resulting from legislation, which entitles individuals to perform specific activities defined by the law(Act No. 311, 2001).

Education can take place either in an organized way between an educator and a learner, or in an unorganized way, where the dominant role in education is assumed by the participants themselves; in this case we refer to the learning process. If we look at education as an organized process, we can define ways of organizing education in relation to the number of participants, the composition of participants, the place of education, its duration and repeatability, and the method used to organize the activities of the education provider and of the participants (Mendíková, 2010).

Every form of education, even further professional education, should be a balanced combination of several aspects. It is naturally centred on cognitive (knowledge) aspects, where knowledge is acquired through systematic study, based on the level of cognition, throughout the stages of information acquisition, sorting, processing, and storage in consciousness, with the idea that the acquired knowledge then undergoes further creative development and use. Regardless of the age of the participants in education, their job position or previous education, one of the requirements of any system of education is to consider the cognitive, emotional, training, and information and communication aspects of learning(Karlovitz, 2016; Porvazník, Ladová, \& Rajošová, 2007).

Another crucial part of LLL is training. Training enables individuals to acquire skills and readiness correctly and as quickly as possible and allows them to perform a certain activity with the least amount of effort, based on the acquired knowledge and previous practical activities. Training is an ongoing part of education aimed at improving skills. The term training also covers the processes of acquiring desired attitudes, behavior, social maturity, and social skills - it is part of educational processes related to the development of emotional aspects. Education is the process of shaping and developing an individual's personality (Mpofu \& Hyathywayo, 2015; Pauknerová, 2012), which is characterized by certain mental and physical characteristics typical of the individual which manifest in all their activities (Szarková, 2009).

Kubínyi and Veteška (2017)discuss the issue of the further professional education of soldiers in the Army of the Czech Republic. They identify the key reasons for soldiers to participate in further professional training (career courses, language education, vocational training, and self-study) and conclude that the education and development of soldiers is key to the acquisition and development of specific skills and knowledge in the military.

Communication, as the process of developing social understanding and interpreting thoughts, opinions, and feelings between two or more individuals, is an important aspect of education. The basis of communication is an individual's ability to effectively present their ideas orally or in writing, and in this way help to integrate knowledge and initiate creative action (Beláňová, 2020).

The focus of our research is on the construction industry, which is a dynamic sector of the economy; it affects not only the construction of new buildings and the reconstruction of existing ones, but also urban and spatial 
planning. It is closely related to environmental engineering, transport engineering, landscape architecture, monument preservation, and cultural heritage (Ahn, Pearce, Wang, \& Wang, 2012; Seho \& Malošíková, 2018).

When formulating the research goals, we focused on the provision of further professional education in the building and construction sector. We were also inspired by the conclusions of the professional conference of the Association of Construction Entrepreneurs of Slovakia (ZSPS): the Slovak Construction Forum, held in March 2017, on trends in vocational education and employment in the building and construction industry (Eurostav, $2017)$.

Our research activities have also been influenced by the need for a long-term solution for education in the construction industry. Further professional education is implemented for the purposes of developing hard as well as soft skills. In the area of hard skills, further education in this industry focuses on individual and mass building and construction, with a focus on the knowledge of new materials, construction and renovation technologies, architectural trends, and developers' and investment projects. However, the scope of education in this industry is much wider. It encompasses the construction and operation of energy-saving, low-energy, and energy-passive buildings as well as trends in "green" architecture, etc.(Ahn et al., 2012).

Equally important, especially in terms of the direct contact with customers, is the education in soft, i.e., nontechnical skills. Soft skills include the personal attributes, personality traits, and emotional intelligence traits necessary for job success (Ibrahim, Boerhannoeddin, \& Bakare, 2017; Schultze \& Roberts, 2007). For further professional education to be useful, the educational needs must be correctly identified, which requires the application of certain methods that can be used in the analytical processes we focus on in our research. The application of appropriate methods of analysis of educational needs, together with a goal-oriented arrangement of the external aspects and conditions (forms of education) under which the educational process is conducted, is a significant contributor to the quality and overall organizational management of the educational event.

Construction organisations and companies operate within a specific business environment, and their educational activities are influenced by their internal needs and requirements, their competitors, and by a number of laws, decrees and government regulations that employees, managers and owners must be familiar with, and which must be reflected in their specific activities.

\section{Literature Review (Theoretical Background)}

The starting point for our reflections on further corporate education is the concept of lifelong education and its roles in contemporary society. Dubcová and Foltínová (2019) explore the concept of lifelong learning (LLL) in relation to age and describe its principles, its advantages, as well as its barriers. They recommend strategies and policies for promoting the adult education model. Their recommendations include an array of financial and economic instruments: the building of consultation centers; courses that ensure the efficient operation of the LLL model; the promotion and organization of special awards and workshops for the purpose; supporting networks of mutual cooperation and marketing tools for LLL activities, etc. Slangal (2018) reflects on the andragogical basis of adult education and its links to andragogy, the andragogical mindset, and self-directed learning. The need for a new approach to lifelong learning is summarized by Veteška and Kursch (2018) in the context of the rapid changes in the modern era. Their research study is an attempt to synthesize the current approaches and limitations in the Education 4.0 paradigm in the lifelong context, namely the function of initial education as a preparation for life and work, and the function of further education, which involves promoting the concept of life long development.

In companies, the management of education is an integral part of the human resources management process. Company training should not be a short-term affair. In order to be effective, it must involve a continuous process implemented along a systems approach (Lifelong Education, 2021; Liles \& Mustian, 2004). This paper will not deal with all the stages of the systems approach; instead, we focus on selected partial aspects, which we will examine both in the description of the underlying theory and the subsequent empirical analysis. These stages involve:

- The identification of training needs (data collection for analysis) as the basis for planning appropriate training.

- Deciding on the type of education.

- The organizational management of education (forms of education).

The management of education is often part of work performance management, which includes requirements for improving individual performance, team performance, and the performance of the entire organization (Koubek, 2004). The correct identification of educational needs is based on appropriate data collection and analysis (Vodák \& Kucharčíková, 2007). The identification of educational needs must be based on the difference between the current state of performance and the required performance to be achieved. The education proposal is then determined by the so-called negative problem, in the form of a specific shortcoming that must be overcome. Conversely, the need for education can also be determined by a positive problem related to the anticipated future needs and requirements of work performance (Karlovitz, 2013; Nuernberg, 2011).

\subsection{Identification of Educational Needs}

- The identification of educational needs, on the basis of which education is subsequently planned and educational projects are prepared, requires the application of a number of methods that facilitate a thorough analysis of said educational needs. In the preparation of this analysis, attention must be paid to data collection. Two approaches are used for the data collection:

- Commonly available information in the employer entity, including, for example: information from employee evaluations, inspections, meetings, discussions, absences, as well as from time-management and productivity evaluations, etc. (Armstrong, 2007; Dvořáková, 2007; Galajdová, 2007; Hroník, 2006; Vetrakova, 2011; Wagnerová, 2008; Walker, 2003).

- Purposefully acquired information using specific methods to identify the specific data required. There are a number of techniques and methods through which researchers can obtain the necessary data for training 
interventions in companies (Dvorakova, 2012; Joniaková, 2016; Koubek, 2015; Matulčíková \& Matulčík, 2019; Szarkova., 2013). They include:

- Structured interview (Koubek, 2015)

- Unstructured interview (Koubek, 2015)

- Observation (Szarkova, 2013)

- Questionnaire survey (Koubek, 2015)

- Participation (Szarkova, 2013)

- Group discussion (Koubek, 2015),

- Descriptions of an employee’s work (Joniaková, 2016)

- Critical event analysis (Mužík, 2011)

- 360-degree feedback (Mužík, 2011)

- 540-degree feedback (Mužík, 2011)

- Motivation and evaluation interview (Zufan, 2012)

- Behavior interview (Doyle, 2020a; Pivovarová, 2017)

- Assessment centers and development centers(Kocianová, 2010; Urban, 2013; Vaculík, 2010)

- Various types of tests, e.g., psychological tests (depending on the type of job), self-assessment etc.(Macková, 2012; Pauknerová, 2012; Szarková, 2009).

Data collection is the starting point for the analysis of educational needs and for a creation of a summary of all data required to plan educational activities. The intention here is to examine not only the required knowledge, skills, and abilities(Bartoňková, 2010) but also the working conditions, job creation principles, evaluation of work activities, physical working conditions, and socio-psychological working conditions.

\subsection{Types of Education}

The activities of further corporate education can generally be divided into mandatory and voluntary education. While compulsory education ensues from a country's legislation, voluntary education is an expression of the employer's interest and desire to provide educational opportunities for their employees, and in this way achieve the required qualitative and quantitative work outcomes. There are more mandatory training activities in the construction industry than in other sectors, which, apart from occupational health and safety, do not regularly include work activities that would necessitate the verification of professional competence within the set deadlines for obtaining or renewing valid certification or authorization to perform specific activities. Education in the field of workplace health and safety has its own specifics in the construction industry and must conform to STN EN ISO standards (e.g., testing of health and safety in welding in The Welding course according to STN EN ISO 14732/521) (Lifelong Education, 2021).

At this point, principles of occupational hygiene, as well as environmental protection and other issues must be mentioned. Voluntary vocational training for construction workers, consisting of adaptation, further qualification training, and retraining, covers a broad range of educational activities (Harper, 2021; Stáfek, Sanova, Novotná, \& Laputková, 2016; Wong \& May, 1998).

Adaptation education is an important part of the adaptation process in construction companies. The aim of both parties, the employer and the employee, is to reconcile professional, psychological, and social needs with working conditions and the working environment as quickly as possible.

Further qualification education focuses on the increase, expansion, innovation, specialization, and renewal of qualifications. In this context, training forms the most basic type of education that can be performed even in the simplest work activities, though this extends to purposeful professional training focused on the ever-increasing demands placed on the performance of individual work activities, up to specialized training associated with new technical and technological innovations, and finally to interdisciplinary approaches in education (McCulloch \& Crook, 2008). Examples of this include digitization in the construction industry, building and spatial acoustics, energy efficiency of buildings, etc. (Building Information Modeling- BIM, 2019).

Special-purpose professional training concerns the organization and management of construction production and the management of production teams in the actual implementation of building construction. This covers the elaboration and implementation of project construction documentation, the selection and use of suitable materials and technological procedures, economical work with materials, energy and machinery, application of financial knowledge, as well as the business activities and investment knowledge needed to compile a construction budget.

When dealing with special-purpose professional training, there is a significant role for the development of soft skills and key competences, although some authors claim there is no strict dividing line between these two groups (Cahn, 2009). According to "The Balance Careers" portal (Doyle, 2020b), soft skills include:

- Adaptability

- Communication

- Creative thinking

- Dependability

- Work ethic

- Teamwork

- Positivity

- Time management

- Motivation

- Problem solving

- Critical thinking

- Conflict resolution 
Other authors define soft skills as character traits (Boroš, 2002; Flešková \& Dolinská, 2010; Tsalikova \& Pakhotina, 2019), will properties (Macková, 2012), and characteristics of emotional intelligence - self-awareness, self-control, motivation, empathy, and social skills (Schultze \& Roberts, 2007; Stuchlíková, 2007; Suchý \& Náhlovský, 2012; Wilding, 2010).

The concept of key competences is used to refer to those competences that are unrelated to a specific job, and which are instead influenced by the level of societal development and the dynamic development of working and living conditions. Key competences are an extension of qualifications and represent the target states of education; their characteristics and content are based on the skills valued by society and on general ideas about which competences contribute most to employment, education, and a happy and successful life. Key competences represent sets of activity-oriented and practically usable outputs, and their acquisition is a long-term and complex process. The European Commission has defined eight key competences for lifelong learning in the European Reference Framework (European Commission, 2019; The Oxford Handbook of Lifelong Learning, 2011; Veteška, 2011):

- Communication in the mother tongue

- Communication in foreign languages

- Mathematical competences and basic competences in the field of science and technology

- Digital competences

- Learning competences

- Social and civic competences

- Sense of initiative and entrepreneurship

- Cultural awareness and the understanding of artistic expression.

Digital literacy (DL) involves not only the skills required to use digital devices but also the ability to create, present, and share information in various modes and formats. It is also understood as the ability to interact, collaborate, and effectively communicate through digital devices, and demonstrate a critical approach to technology. Tomczyk (2018) views DL as a complex phenomenon, consisting of numerous elements, while its technical aspects also include searching, differentiating, editing, and processing. Tomczyk differentiates between digital natives (people who have not known a world without electronic media) and those who naturally have the skills of using ICT tools(Tomczyk, 2018).

The topic of adult education has been explored in a broad context and from various angles. While some authors (e.g.,Pavlov \& Neupauer, 2019; Veteška. \& Kursch, 2018) are optimistic about the human potential for learning in relation to digitization and artificial intelligence, others point to potential negative implications (Ullrich, Ambrozová, Koleňák, \& Pokorný, 2019). Ullrich et al. (2019) discuss the advantages and possible pitfalls of digitization in the context of the changing demands related to the development of industry and society 4.oplaced on professionals and managers, and identify three types of digitization 'shade effects'. The first concerns a change in the quality of awareness; the second occurs in the structuring of data, information and knowledge, as well in their representation; the third is connected with the rise in digitization and algorithmization and artificial intelligence, which results in a decrease in the contribution of intuition and analogy in cognition processes, as well as in decline in decision-making abilities and reduced flexibility in responding to changes(Ullrich et al., 2019).

Closely linked to the need for increasing employment in the construction industry is the need for retraining, which is currently on a declining trend. Retraining can be implemented as:

- Targeted retraining -changing an individual's qualifications by teachingthe knowledge, skills and habits needed for a new profession, usually targeted at a specific job in the company. This type of retraining is associated with achange in the individual's work orientation. It is often implemented in a formal education system.

- Retraining in a related area -this type refers to additional training, supplementing the knowledge of the employee or jobseeker according to the requirements of the employer. It is often the result of non-formal education. Retraining is a significant contributor to therecruitment of workers in the construction industry; frequently,however,unskilled workers are unable to achieve the requiredperformance level.The construction industry must be made more attractive in formal education.

\subsection{Organization of Education (Forms of Education)}

An important part of education planning is the organization of education. Individual forms of education are characterized by the goal-oriented arrangement of external sites and the conditions under which the educational process is implemented. The different forms of education can be classifiedaccording to several factors, including: the number of participants, composition of participants, venue, timing of education, repeatability of education, and ways of organizing the activities of educators and participants. Vocational training within the framework of further professional education is usually carried out either full-time or online, in the form of webinars (Eurostav, 2017).

Another accompanying feature of the organization of education is the number of participants involved; this applies to the development of both hard and soft skills in the construction industry, where education is provided in individual, group and collective forms. In the case of individual education, there is generally a singlelearner, up toamaximum number of three. A group should consist of no more than twenty participants, althoughfor some specific courses, a maximum of twelve participants is recommended. These forms of education are further detailed below.

- Individual education - takes the form of self-study, consultations, and practice (demanding a form of organization that preparesparticipants/trainees for their occupation/profession). It is most often carried out in the work environment in the form of laboratory work or professional practice.

- Group education - group instruction should form the basis for active learning. The group participant should feel happier and more relaxed. The lecturer works as an organizer and coordinator of work, and an instructor and consultant of participants/learners. The activity is largely carried out by the participants. The seminar form helps to systematize the acquired knowledge, supplement the experience, and broaden the learners' 
horizons about a given topic or problem. An active relationship with the field of study is developed and the learners' creative abilities and skillsare developed and improved. Goup educationmainly fulfils the functions of training, reproduction, strengthening, and application (training of manual skills and habits).

- Mass education, or frontal learning - the most frequent frontal organizational form of adult education is plenaryteaching. The term plenaryis used herein its meaningof 'universal'. Basically, it is synonymous with the term 'lecture', in the sense of the organizational form of teaching at universities, and the term 'lesson',in secondary and primary education. The maximum number of participants in the plenary should not exceed eighty, so that the teacher can perceive and communicate with them.

It is necessary to note the distinctionbetween individual education andindividualized education, which is tailormade. Thisfocuses on the needs and potentialof specific participants and assumes the introduction of a system of diagnostics and spatial and temporal individualization of education (Prusáková, 2001), which is important in some jobs and activities in the construction industry.

In the implementation of further professional education, other forms of education are also often used to allow for the best possible organizational management of education; in this context, open forms and also participatory and cooperative forms of education should be mentioned. The effectiveness of education in the workplace can be increased by a creative approach to the application of modern technology. In her paper,Kubálková (2017)discusses the development and application of video recordings in workplace education both in terms of their costs and their conditions of use (their time-consuming nature) and provides three recommendations. The first is to create a video of a lecture or training, which is the least time-consuming option. Secondly, a simple desktop recording is recommended for regular tutorials, as the costs of equipment and staffing are not high. Finally, a complete MOOC course is considered to be the most time-consuming to produce.

\subsection{Summary}

Deciding on the most suitable types and forms of corporate education in the construction industry is of crucial importance due to the organizational complexity and work conditions in the sector. The focus of our paper is on further education, as a part of lifelong learning, in construction companies in Slovakia. Given the wide range of issues, we focus on three major areas, namely: the process of preparing and planning educational activities (identification of educational needs); kinds of education; and current trends in vocational education in accordance with the current development needs of the construction industry, as well as the organization of educational activities.

\section{Research Framework and Methodology}

The main aim of this paper is to explore Slovakian construction companies 'approach to further professional education. Based on a questionnaire survey, our intention was to identify any weaknesses in the detection of educational needs and point out the kinds and forms of education implemented, in order to improve the organization of further professional education, and in this way contribute to increasing its effectiveness and quality.

The research consisted of three main stages, as illustrated in Figure 1. In Stage 1 we focused on a study of the scholarly and professional literature dealing with the following three significant areas: data collection processes for the identification of educational needs, kinds of education, and trends in professional training required to adjust to contemporary development needs in the construction industry, as well as the organization of educational activities. In Stage 2, the research assumptions and research hypotheses were formulated. At the same time, the research model (model of research indicators) was developed for their verification. Stage 3 consisted of the statistical verification of hypotheses and the formulation of conclusions.

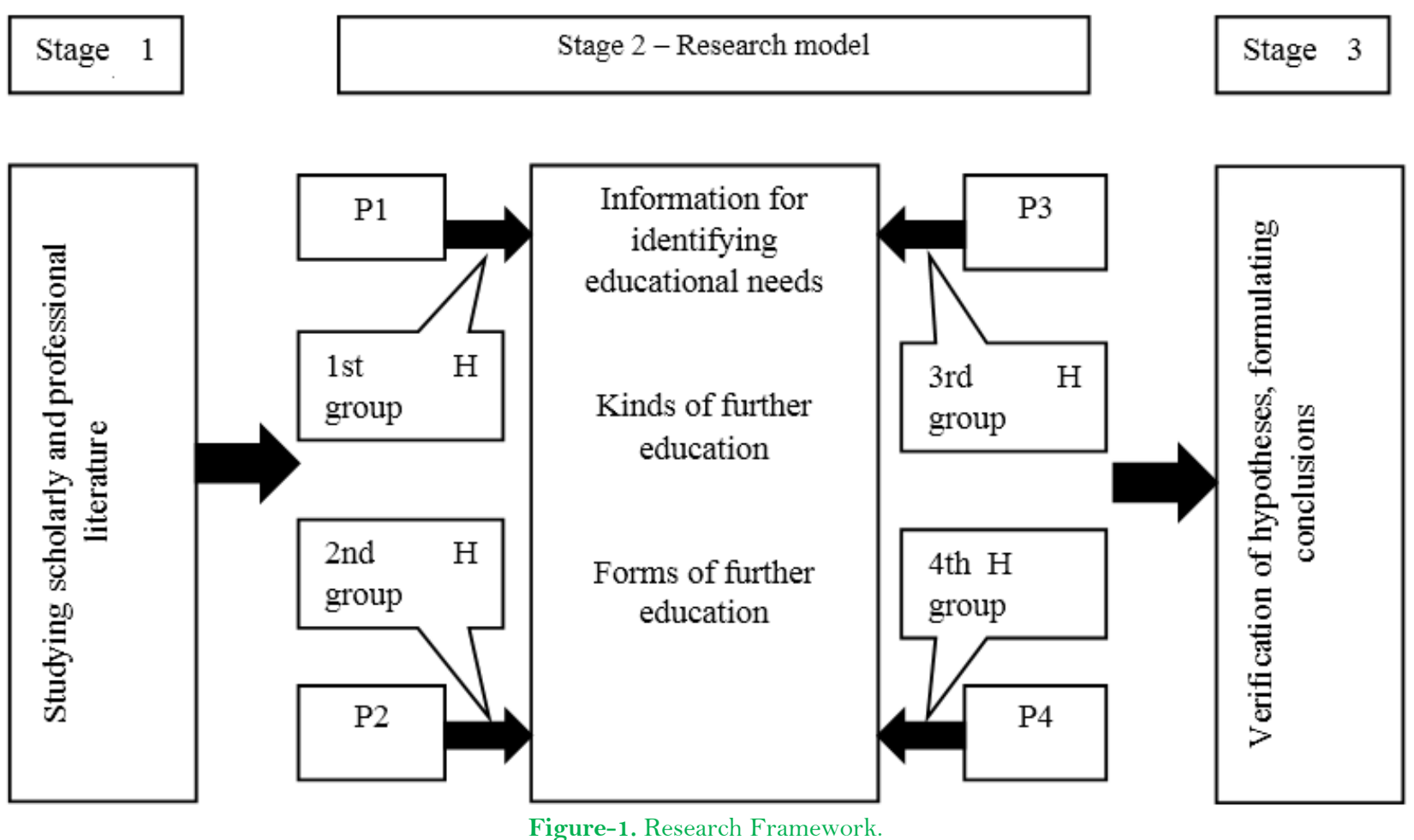

Figure-1. Research Framework. 
Table-1.Model of research indicators \begin{tabular}{l}
\hline Indicator \\
\hline I. Types of data used in assessing educational needs \\
\hline A
\end{tabular} Information/data used in assessing educational needs

A 1

Commonly available data

A2

Special-purpose acquired information - their methods of acquisition

\section{Indicator value}

A1Commonly available information/data

A2 Special-purpose acquired information/data

A3 Data acquired commonly and for a special purpose

A11 Information/data from employee assessment

A12 Information/data from internal controls

A13 Data from external controls

A 14 Legislation data

A 15 Others

A21 Structured interview

A22 Unstructured interview

A23 Observation

A24 Questionnaire research/survey

A25 Participation

A26 Group discussion

A27 Job descriptions created by an employee

A28 Critical event analysis

A29 360-degree feedback

A210 540-degree feedback

A2 11 Motivation - evaluation interview

A212 Behavioral interview

A213 Assessment centers and development centers

A214 Various types of tests (psychological tests, self-assessment, etc.)

A215 Others

\begin{tabular}{l} 
II.Education \\
\hline B Kinds of education
\end{tabular}

B2 Voluntary education

B1 Mandatory

B2 Voluntary

B3 Mandatory and voluntary

B21 Qualification

B22 Retraining

B23 Qualification and retraining

B24 Others

B211 Hard skills

B212 Soft skills and key competences

B213 Hard skills, soft skills and key competences

B214 Others

B2111Adaptation

B2112 Introductory training

B2113 Special-purpose professional preparation

B2 114 Specialization training preparation

B2115 Special-purpose professional preparation and specialization

B2116 Adaptation training

B2117 Special-purpose professional preparation, specialization preparation, and adaptation training

B2118 Others

B221 Target retraining - change in current qualification

B222 Retraining in related area

B223 Others

III. Forms of education

C1 Forms of education by number of participants

C2 Managed forms of education
C11 Individual

C12 Individual and group

C13 Group

C14 Collective

C15 Group and collective

C16 Individual, group and collective

C17 Individual and collective C18 Others

C21 Self-access study

C22 Self-access study and full-time study

C23 Full-time study

C24 Distance

C25 Self-access study, full-time and distance

C26 Hybrid (full-time and distance)

C27 Self-access and distance

C28 Others

3.1. Research Assumptions and Research Hypotheses

The following assumptions formed the foundation of the research:

1. The approach to further education in the Slovakian construction industry differs between men and women.

2. People with higher education who work in Slovakian construction companies are more interested in continuing their education, which is reflected in a higher percentage of selected indicators. 
3. The job position of people working in Slovakian construction companies influences their approach to further education. Managers are more interested in further education than non-managerial employees, which is reflected in a higher percentage of selected indicators.

4. The approach to further education differs according to company size (micro-, medium-sized and large construction companies). Large companies are more interested in education than small and medium-sized companies, which is manifested in a higher percentage of selected indicators.

To verify the research assumptions, four groups of research hypotheses were developed, which are formulated as a zero hypothesis and alternative hypothesis.

1st group of hypotheses:

1 Hoa: The gender of respondents does not have a significant statistical influence on their approach to further education.

$1 \mathrm{H} 1 \mathrm{~b}$ : The gender of respondents has a significant statistical influence on their approach to further education.

2nd group of hypotheses:

2 Hoa: The level of completed education of respondents does not have a significant statistical influence on their approach to further education.

$2 \mathrm{H} 1 \mathrm{~b}$ : The level of completed education of respondents has a significant statistical influence on their approach to further education.

3rd group of hypotheses:

3 Hoa: The respondent's job position does not have a significant statistical influence on the respondent's approach to further education.

3 H1b: The respondent's job position has a significant statistical influence on the respondent's approach to further education.

4th group of hypotheses:

4. Hoa: The size of the respondent's company does not have a significant statistical influence on the respondent's approach to further education.

H1b: The size of the respondent's company has a significant statistic influence on the respondent's approach to further education

\subsection{Methodology}

Standard methods of scientific work (analysis, comparison and selection) were used in the study of the literature. The main method used was a questionnaire survey, which was conducted from October 2019 to October 2020 on a sample of 108 companies, which operate within Slovakia's construction industry. The questionnaire was created on the basis of a research model and consisted (in addition to basic parameters) of three groups of questions focused on three areas of research, namely, how to obtain information to identify educational needs, types of education, and forms of education. The questionnaire was multiple choice. Descriptive statistics methods and contingency tables were used to evaluate the results. The hypotheses were tested using statistical methods and coefficients suitable for measuring the relationships between nominal or dichotomous variables: chí square, Cramer's V and the Goodman-Kruskal coefficient $\lambda$ (Hanák, 2016). Analysis was carried out by means of statistics software PSPP.

\subsection{Model of Research Indicators}

The model of research indicators is presented in Table 1. Note: the codes of indicators and their values (A, B, $\mathrm{C})$, are given, due to their subsequent use in analysis using the PSPP program.

\section{Results and Discussion}

The results are presented according to the following structure: research sample, results of individual indicators according to the research model, and results of statistical analysis.

\subsection{Research Sample}

The research sample consisted of 108 respondents, who were divided into groups according to parameters $\mathrm{P} 1-$ gender, $\mathrm{P}_{2}$ - education, $\mathrm{P}_{3}$ - job position, and $\mathrm{P}_{4}$ - size of company for which they work, as illustrated in Table 2.

\begin{tabular}{|c|c|c|c|}
\hline Parameter & Parameter value & Number of respondents & \% of incidence \\
\hline \multirow{2}{*}{$\begin{array}{l}\text { P1 } \\
\text { Gender }\end{array}$} & men & 103 & $95.37 \%$ \\
\hline & women & 5 & $4.63 \%$ \\
\hline \multirow{7}{*}{$\begin{array}{l}\mathrm{P} 2 \\
\text { Education }\end{array}$} & primary & $\mathrm{O}$ & $0.00 \%$ \\
\hline & secondary - apprenticeship certificate & 24 & $22.22 \%$ \\
\hline & secondary - GCSE & 50 & $46.30 \%$ \\
\hline & university (higher) $1^{\text {st }}$ level & 12 & $11.11 \%$ \\
\hline & higher- $2^{\text {nd }}$ level & 22 & $20.37 \%$ \\
\hline & higher $-3^{\text {rd }}$ level & $\mathrm{O}$ & $0.00 \%$ \\
\hline & others & $\mathrm{O}$ & $0.00 \%$ \\
\hline \multirow{4}{*}{$\begin{array}{l}\text { P3 } \\
\text { Job position }\end{array}$} & self-employed & 40 & $37.04 \%$ \\
\hline & manager & 66 & $61.11 \%$ \\
\hline & employee & $\mathrm{O}$ & $0.00 \%$ \\
\hline & owner & 2 & $1.85 \%$ \\
\hline \multirow{4}{*}{$\begin{array}{l}\mathrm{P} 4 \\
\text { Company size }\end{array}$} & micro-company (self-employed) & 40 & $37.04 \%$ \\
\hline & small company & 42 & $38.84 \%$ \\
\hline & medium-sized company & 11 & $10.19 \%$ \\
\hline & large company & 15 & $13.89 \%$ \\
\hline
\end{tabular}


The research sample was evaluated according to the separate parameters:

The research sample included mostly men (over 95\%), which is not unnatural in the construction industry. However, this parameter has not been excluded from further analysis, in order to obtain current results (depending on the purpose of the paper and the research assumptions) and to formulate proposals and recommendations for further research.

As for education, most respondents had completed their secondary education with a GCSE (46.30\%) oran apprenticeship certificate (22.22\%). A relatively high proportion of respondents was university-educated, namely $1.11 \%$ at the first level, and $20.37 \%$ at the second level.

Look at parameter P3, the research sample consisted of 61.11\% managers of construction companies and $37.04 \%$ self-employed persons. The size of companies represented by parameter P4 covered all the values examined. Microcompanies $(37.04 \%)$ and small enterprises $(38.84 \%)$ had the largest share. The values of all parameters which reached an occurrence of $<5$ were excluded from further analysis.

\subsection{Results of Evaluation of Separate Indicators}

The values of individual indicators and their percentages are presented in Table 3, Table 4, and Table 5.

Table-3.Evaluation of Group 1 indicators

\begin{tabular}{|c|c|c|c|}
\hline \multicolumn{4}{|c|}{ I. Types of data used in assessing educational needs } \\
\hline Indicator & Value & Number of answers & \% of incidence \\
\hline \multirow[t]{3}{*}{$\overline{\mathrm{A}}$} & $\mathrm{A} 1$ & 54 & $50.47 \%$ \\
\hline & A2 & 3 & $2.80 \%$ \\
\hline & A3 & 50 & $46.73 \%$ \\
\hline \multirow[t]{5}{*}{ A1 } & A11 & 50 & $46.73 \%$ \\
\hline & A 12 & 21 & $19.63 \%$ \\
\hline & A 13 & 4 & $3.74 \%$ \\
\hline & A 14 & 29 & $27.10 \%$ \\
\hline & A 15 & 3 & $2.80 \%$ \\
\hline \multirow[t]{15}{*}{ A2 } & A21 & 3 & $2.80 \%$ \\
\hline & A22 & 4 & $3.74 \%$ \\
\hline & A23 & 20 & $18.69 \%$ \\
\hline & A24 & 3 & $2.80 \%$ \\
\hline & A25 & $\mathrm{O}$ & $0.00 \%$ \\
\hline & A26 & 5 & $4.67 \%$ \\
\hline & A227 & $\mathrm{O}$ & $0.00 \%$ \\
\hline & A28 & $\mathrm{O}$ & $0.00 \%$ \\
\hline & A29 & $\mathrm{O}$ & $0.00 \%$ \\
\hline & A210 & 2 & $1.87 \%$ \\
\hline & A211 & 10 & $9.35 \%$ \\
\hline & A212 & 6 & $5.61 \%$ \\
\hline & A2 13 & $\mathrm{O}$ & $0.00 \%$ \\
\hline & A2 14 & $\mathrm{O}$ & $0.00 \%$ \\
\hline & A2 15 & 54 & $50.47 \%$ \\
\hline
\end{tabular}

The educational needs of companies are identified based only on commonly available data in $50.47 \%$ of cases. $46.73 \%$ of companies add special-purpose data to their assessment process. Only $2.80 \%$ of companies focus exclusively on the data acquired for a special purpose.

Of the commonly available data, the highest proportion was obtained from employee appraisals (46.73\%), followed by legislation data (27.10\%), and information from internal controls (19.63\%).

Respondents found it difficult to identify their methods of acquiring special-purpose data, since as many as $50.47 \%$ of them marked the indefinite option - other(s). Of the identified methods of acquiring special-purpose data, more than $10 \%$ of the respondents mentioned only observation $(18.69 \%)$.

Respondents also found it difficult to specify their answers more precisely regarding retraining education (requalification) and also to be more specific in the description of hard skills. In the case of retraining education, as many as $62.62 \%$ of respondents selected the option 'other(s)', 25.23\% the option 'retraining in a related area/field', and $12.15 \%$ marked the option 'targeted retraining - change in the current qualification'.

As regards the kinds of education offered, 33.64\% of companies are engaged only in compulsory education, while up to $66 \%$ offer both mandatory and voluntary education. Of the respondents who mentioned both mandatory and voluntary education, the majority (66.35\%) stated qualification education, of whom $30.84 \%$ marked it together with retraining.

The answers regarding qualification education follow a similar pattern. 35.51\% of companies focus on qualification education/training to acquire hard skills, soft skills, and key competencies, 30.84\% focus exclusively on the acquisition of hard skills, and 33.64\% marked an indefinite answer 'other'.

Similarly, in the case of education focused on the acquisition of hard skills, the highest percentage was recorded in the indefinite option of 'other(s)' (33.64\%). Of the remaining options, it is worth mentioning the adaptation of hard skills (30.84\%); special purpose professional preparation, specialization preparation and adaptation introductory training (24.30\%); adaptation introductory training by itself (22.43\%); and the combination of specialpurpose professional preparation and specialization preparation (10.28\%). The other options achieved values smaller than $10 \%$. 
Table-4. Results of evaluation of Group 2 indicators.

\begin{tabular}{|c|c|c|c|}
\hline \multicolumn{4}{|c|}{ II. Kinds of education } \\
\hline Indicator & Value & Number of answers & $\%$ of incidence \\
\hline \multirow[t]{3}{*}{ B } & $\mathrm{B} 1$ & 36 & $33.64 \%$ \\
\hline & B2 & $\mathrm{O}$ & $0.00 \%$ \\
\hline & B3 & 71 & $66.36 \%$ \\
\hline \multirow[t]{4}{*}{$\overline{\mathrm{B} 2}$} & $\mathrm{~B} 21$ & 38 & $35.51 \%$ \\
\hline & B22 & $\mathrm{O}$ & $0.00 \%$ \\
\hline & B23 & 33 & $30.84 \%$ \\
\hline & $\mathrm{B} 24$ & 36 & $33.64 \%$ \\
\hline \multirow[t]{4}{*}{$\mathrm{B} 21$} & B2 11 & 33 & $30.84 \%$ \\
\hline & B2 12 & $\mathrm{O}$ & $0.00 \%$ \\
\hline & B213 & 38 & $35.51 \%$ \\
\hline & B2 14 & 36 & $33.64 \%$ \\
\hline \multirow{8}{*}{$\mathrm{B} 211$} & B2111 & 2 & $1.87 \%$ \\
\hline & B2112 & 7 & $6.54 \%$ \\
\hline & B2113 & 1 & $0.93 \%$ \\
\hline & B2114 & $\mathrm{O}$ & $0.00 \%$ \\
\hline & B2115 & 11 & $10.28 \%$ \\
\hline & B2116 & 24 & $22.43 \%$ \\
\hline & B2117 & 26 & $24.30 \%$ \\
\hline & B2118 & 36 & $33.64 \%$ \\
\hline \multirow[t]{3}{*}{$\mathrm{B} 22$} & B221 & 13 & $12.15 \%$ \\
\hline & B222 & 27 & $25.23 \%$ \\
\hline & $\mathrm{B} 223$ & 67 & $62.62 \%$ \\
\hline
\end{tabular}

Table-5. Results of Group 3 indicators evaluation

\begin{tabular}{c|c|c|c}
\hline II. Forms of education & \multicolumn{2}{c}{} \\
\hline Indicator & Value & Number of answers & \% of incidence \\
\hline \multirow{4}{*}{ C1 } & C11 & 43 & $40.19 \%$ \\
\cline { 2 - 4 } & $\mathrm{C} 12$ & 38 & $35.51 \%$ \\
\cline { 2 - 4 } & $\mathrm{C} 13$ & 0 & $0.00 \%$ \\
\cline { 2 - 4 } & $\mathrm{C} 14$ & 0 & $0.00 \%$ \\
\cline { 2 - 4 } & $\mathrm{C} 15$ & 8 & $7.48 \%$ \\
\cline { 2 - 4 } & $\mathrm{C} 16$ & 18 & $16.82 \%$ \\
\cline { 2 - 4 } & $\mathrm{C} 17$ & 0 & $0.00 \%$ \\
\cline { 2 - 4 } & $\mathrm{C} 18$ & 0 & $0.00 \%$ \\
\cline { 2 - 4 } & $\mathrm{C} 21$ & 21 & $19.63 \%$ \\
\cline { 2 - 4 } & $\mathrm{C} 22$ & 0 & $0.00 \%$ \\
\cline { 2 - 4 } & $\mathrm{C} 23$ & 0 & $0.00 \%$ \\
\cline { 2 - 4 } & $\mathrm{C} 24$ & 17 & $29.99 \%$ \\
\cline { 2 - 4 } & $\mathrm{C} 25$ & 33 & $28.04 \%$ \\
\cline { 2 - 4 } & $\mathrm{C} 26$ & 30 & $6.54 \%$ \\
\cline { 2 - 4 } & $\mathrm{C} 27$ & 7 & $0.00 \%$ \\
\hline
\end{tabular}

Table 5 conveys the results of the indicators characterizing the various forms of education. Of the forms of education defined by the number of students, the highest value was achieved by individual training/education $(40.19 \%)$, followed by individual training and group training $(35.51 \%)$, and the combination of individual, group and mass training (16.82\%). Zero valueswere achieved by group education on its own, collective training, and individual and collective training; likewise, $0 \%$ of respondents marked the 'others' option. Of the forms of education defined by management structure, in the respondents' companies the combined forms (namely self-study, full-time and distance learning) recorded the highest percentage (29.91\%), followed by hybrid education (full-time and distance) (28.04\%), then self-access study (19.63\%) and distance learning (15.89\%). The combination of self-access study and distance learning also achieved a non-zero value (6.54\%). None of the respondents mentioned full-time education by itself or the 'others' option.

\subsection{Results of Statistical Analysis (Exploration of Mutual Relations)}

Mutual relationships were studied by means of suitable statistical tests and coefficients. According to the research model, our variables achieve nominal values; for their analysis, a chí squared test and coefficients Cramer's V and coefficient Goodman \& Kruskal's $\lambda$ (Hanák, 2016) are used. The results of the statistical analysis are presented in Tables 6, 7, 8 and Table 9 .

Table-6. Results of analyzing differences by gender (P1)

\begin{tabular}{c|c|c|c|c}
\hline Relation & Chi square & df & Cramer's V & Goodman \&Kruskal's $\boldsymbol{~}$ \\
\hline $\mathrm{A} / \mathrm{P} 1$ & 2.42 & 2 & 0.15 & 0.06 \\
\hline $\mathrm{A} 1 / \mathrm{P} 1$ & 3.15 & 4 & 0.17 & 0.00 \\
\hline $\mathrm{A} 2 / \mathrm{P} 1$ & $16.69^{*}$ & 8 & 0.39 & 0.04 \\
\hline $\mathrm{B} / \mathrm{P} 1$ & 2.73 & 1 & 0.16 & 0.00 \\
\hline $\mathrm{B} 2 / \mathrm{P} 1$ & $6.33^{*}$ & 2 & 0.24 & 0.04 \\
\hline $\mathrm{B} 21 / \mathrm{P} 1$ & $9.66^{* *}$ & 2 & 0.30 & 0.06 \\
\hline $\mathrm{B} 211 / \mathrm{P} 1$ & 5.60 & 6 & 0.23 & 0.04 \\
\hline $\mathrm{B} 22 / \mathrm{P} 1$ & $9.92^{* *}$ & 2 & 0.30 & $0.10^{*}$ \\
\hline $\mathrm{C} 1 / \mathrm{P} 1$ & $15.49^{* *}$ & 4 & 0.38 & $0.06^{*}$ \\
\hline $\mathrm{C} 2 / \mathrm{P} 1$ & 6.49 & 4 & 0.25 & 0.00 \\
\hline Note: $* \mathrm{p}<0.05 * * * \mathrm{p}<0.01 * * * \mathrm{p}<0.001$ & & &
\end{tabular}


Statistically significant results are evident in the case of five relationships, as documented by the statistical significance of the Chi square coefficient; Cramer's V varies from 0.24 to 0.39. Although the coefficient is not negligible, it is rather low, which means that although there is a certain relationship, it is not a strong one. This is also documented by the $\lambda$ coefficient, which reaches a low value (from 0.04 to 0.10), while it is statistically significant in only two cases. Based on these results, we reject the $1 \mathrm{H} 1$ hypothesis and accept the 1 Ho hypothesis. This means that the gender of the respondent does not significantly affect their access to further education.

\begin{tabular}{c|c|c|c|c}
\multicolumn{5}{c}{ Table-7. Results of analysis of differences by education $\left(\mathrm{P}_{2}\right)$} \\
\hline Relation & Chi square & $\mathbf{d f}$ & Cramer's V & Goodman \&Kruskal's $\boldsymbol{0}$ \\
\hline $\mathrm{A} / \mathrm{P} 2$ & $20.60^{* *}$ & 6 & 0.31 & $0.23^{*}$ \\
\hline $\mathrm{A} 1 / \mathrm{P} 2$ & 16.96 & 12 & 0.23 & 0.02 \\
\hline $\mathrm{A} 2 / \mathrm{P} 2$ & $46.16^{* *}$ & 24 & 0.38 & 0.04 \\
\hline $\mathrm{B} / \mathrm{P} 2$ & $36.37^{* * *}$ & 3 & 0.58 & $0.38^{* *}$ \\
\hline $\mathrm{B} 2 / \mathrm{P} 2$ & $37.13^{* * *}$ & 6 & 0.41 & $0.24^{* *}$ \\
\hline $\mathrm{B} 21 / \mathrm{P} 2$ & $40.17^{* * *}$ & 6 & 0.43 & $0.30^{*}$ \\
\hline $\mathrm{B} 211 / \mathrm{P} 2$ & $50.70^{* * *}$ & 18 & 0.40 & $0.20^{* * *}$ \\
\hline $\mathrm{B} 22 / \mathrm{P} 2$ & $15.30^{*}$ & 6 & 0.27 & $0.03^{*}$ \\
\hline $\mathrm{C} 1 / \mathrm{P} 2$ & $48.01^{* * *}$ & 12 & 0.38 & $0.22^{* * *}$ \\
\hline $\mathrm{C} 2 / \mathrm{P}_{2}$ & $65.80^{* * *}$ & 12 & 0.45 & $0.23^{* *}$
\end{tabular}

Table 7 contains the results of the statistical analysis of the investigated indicators according to the level of completed education. Varying degrees of statistical significance, documented by value $\mathrm{p}<0.05, \mathrm{p}<0.01$ and $\mathrm{p}<0.001$ within Chi square coefficients, were displayed by all the explored relationships aside from the relationship A $1 / \mathrm{P}_{2}$ (commonly available data/education). Value $\mathrm{p}>0.05$ was obtained in the case of the relation between commonly available data/education, which can be considered natural, as anybody can obtain commonly available data. In the case of the statistically significant relationships, Cramer's V achieved values ranging from 0.27 to 0.58 , which can be considered a medium strong relationship. The causal association measured by Goodman-Kruskal's $\lambda$ varies from 0.20 to 0.38 , which can also be considered a medium strong relationship.

Based on these results, we reject hypothesis $2 \mathrm{Ho}$ and accept hypothesis $2 \mathrm{H} 1$. This means that the respondents' level of completed education has a statistically significant effect on their approach to further education.

Table-8. Results of analysis of the differences by job position (P3).

\begin{tabular}{c|c|c|c|c}
\hline Relation & Chi square & df & Cramer's V & Goodman \&Kruskal's $\boldsymbol{1}$ \\
\hline $\mathrm{A} / \mathrm{P} 3$ & $26.15^{* * *}$ & 4 & 0.35 & $0.40^{* *}$ \\
\hline $\mathrm{A} 1 / \mathrm{P} 3$ & 14.58 & 8 & 0.26 & 0.10 \\
\hline $\mathrm{A} 2 / \mathrm{P} 3$ & $36.49^{* *}$ & 16 & 0.41 & 0.02 \\
\hline $\mathrm{B} / \mathrm{P} 3$ & $52.81^{* * *}$ & 2 & 0.70 & $0.59^{* * *}$ \\
\hline $\mathrm{B} 2 / \mathrm{P} 3$ & $58.28^{* * *}$ & 4 & 0.52 & $0.36^{* * *}$ \\
\hline $\mathrm{B} 21 / \mathrm{P} 3$ & $57.00^{* * *}$ & 4 & 0.51 & $0.41^{* * *}$ \\
\hline $\mathrm{B} 211 / \mathrm{P} 3$ & $91.33^{* * *}$ & 12 & 0.65 & $0.28^{* * *}$ \\
\hline $\mathrm{B} 22 / \mathrm{P} 3$ & $41.12^{* * *}$ & 4 & 0.44 & 0.05 \\
\hline $\mathrm{C} 1 / \mathrm{P} 3$ & $94.12^{* * *}$ & 8 & 0.66 & $0.52^{* * *}$ \\
\hline $\mathrm{C} 2 / \mathrm{P} 3$ & $103.08^{* * *}$ & 8 & 0.69 & $0.28^{* * *}$
\end{tabular}

The results of the statistical analysis of indicators according to job position display a statistically significant influence of the $\mathrm{P} 3$ parameter (aside fromA1/P3 commonly available data/job position relationship), which is documented by the values $\mathrm{p}<0.05, \mathrm{p}<0.01$ and $\mathrm{p}<0.001$ within the Chi square coefficients. As in the preceding table, the value $\mathrm{p}>0.05$ occurred in the case of the relationship between commonly available data and education, which is again considered natural, as the commonly available data can be acquired by anyone.

In the case of statistically significant relationships, Cramer's V achieved values ranging from 0.35 up to 0.70 , which represent a medium to high relationship strength. This is confirmed by Goodman-Kruskal's $\lambda$, which varies from 0.28 to 0.59 , and in seven cases of nine it displays a statistically significant relationship p $<0.01, \mathrm{p}<0.001$. Based on these results, we reject the $3 \mathrm{Ho}$ hypothesis and accept the $3 \mathrm{H} 1$ hypothesis. This means that the respondent's role within their company has a statistically significant influence on their approach to further education.

Table-9. Results of verification of differences by company size ( $\mathrm{P} 4)$.

\begin{tabular}{|c|c|c|c|c|}
\hline Relation & Chi square & df & Cramer's V & Goodman \&Kruskal's $\lambda$ \\
\hline $\mathrm{A} / \mathrm{P} 4$ & $42.28 * * *$ & 6 & 0.44 & $0.43^{* * * *}$ \\
\hline $\mathrm{A} 1 / \mathrm{P} 4$ & $19.79^{*}$ & 12 & 0.25 & 0.10 \\
\hline $\mathrm{A}_{2} / \mathrm{P}_{4}$ & $70.98 * * *$ & 24 & 0.47 & $0.15^{* *}$ \\
\hline $\mathrm{B} / \mathrm{P} 4$ & $54.20 * * *$ & 3 & 0.71 & $0.59 * * *$ \\
\hline $\mathrm{B} 2 / \mathrm{P}_{4}$ & $118.06 * * * *$ & 6 & 0.74 & $0.70^{*} * * *$ \\
\hline $\mathrm{B} 21 / \mathrm{P} 4$ & $88.30 * * *$ & 6 & 0.64 & 0.59 **** \\
\hline $\mathrm{B} 211 / \mathrm{P} 4$ & $101.61 * * *$ & 18 & 0.56 & $0.38 * * * *$ \\
\hline $\mathrm{B} 22 / \mathrm{P}_{4}$ & $72.67 * * *$ & 6 & 0.58 & $0.40^{*} * * *$ \\
\hline $\mathrm{C}_{1} / \mathrm{P}_{4}$ & $197.33^{* * * *}$ & 12 & 0.78 & $0.80^{* * * *}$ \\
\hline $\mathrm{C}_{2} / \mathrm{P}_{4}$ & $145.82^{* * * *}$ & 12 & 0.67 & $0.55 * * *$ \\
\hline
\end{tabular}

As in the previous two cases, the results of the statistical analysis of the examined indicators according to company size confirm the statistically significant influence of the $\mathrm{P} 4$ parameter, as shown in Table 9, which 
demonstrates the statistical significance of the Chi square coefficient for all tested relationships. Cramer's V reaches values ranging from 0.25 to 0.74 , representing relationships of medium to higher strength. This is confirmed by Goodman-Kruskal's $\lambda$, which ranges from 0.15 to 0.80 and in eight cases out of nine displays a statistically significant relationship $\mathrm{p}<0.01, \mathrm{p}<0.001$. Based on these results, we reject hypothesis 4 Ho and accept hypothesis $4 \mathrm{H} 1$. This means that the size of the company for which the respondent works has a statistically significant effect on his/her approach to further education.

\section{Conclusion}

The main aim of this paper was to explore the approach of Slovakian construction companies to selected attributes of further corporate education, both in their methods for detecting educational needs, as well as in the different kinds and forms of education they choose to implement. Based on hypotheses it was examined whether assumptions regarding a differing approach to further education on the basis of gender, level of completed education, job position, and company size were corroborated.

The conclusions are described in two sections, namely the conclusions drawn from the evaluation of data collected through descriptive statistics and the conclusions based on the statistical analysis of the results.

\subsection{Conclusions Based on the Evaluation of Data Collection}

Relevant comments on the assessment of the collected data are provided under the pertinent tables (Table 3, Table 4, and Table 5).

The identification of educational needs based on correct data and information is a prerequisite for the implementation of properly targeted further education. We found that in most Slovakian construction companies management rely on commonly available as well as special-purpose information, which can be considered adequate. However, little is known about the methods for obtaining special-purpose information. Of the methods suggested in the survey, the most frequently mentioned is the method of observation. In observation, the person holding the role of observer typically compares individuals' abilities and skills with their performance, which should comply with prescribed standards and work procedures. Observation can also be combined with other methods and is most often associated with the various types of interviews. Interviews can take several forms, namely as either structured or unstructured, or as a motivational evaluation interview. Currently, behavioral interviews are gaining popularity, and we recommend these to construction companies.

As for the kinds of education/training, approximately two-thirds of companies provide both mandatory and voluntary education, in which qualification education prevails, while a combination of qualification education and retraining is provided to a lesser extent.

The importance of qualification education confirms the complex nature of the work in the construction industry and the continual changes in technology. Within qualification education, adaptation education is of the greatest importance, as is plays a significant role in the adaptation process of a company. The goal of both the employer and the employee is to reconcile professional, psychological, and social needs with working conditions and the working environment as quickly as possible, which can be considered an important factor contributing to work outcomes in the construction industry. The reconciliation process can take place within a company when a new employee joins the company, or when applying methods of intra-company employee mobility - for example, when moving an employee to another job or relocating them to perform their job in another location (abroad). Equally important was the combination of adaptation education with introductory training. Introductory training, unlike adaptation education, is designed for the simplest work activities. Junior managers, supervisors, experienced employees, as well as human resources professionals and training specialists are constantly involved in introductory training activities. In addition, experts who carry out the relevant work activities on a long-term basis are generally involved in introductory training (providing introductory instructions and practical advice).

A significant number of respondents commented on the importance of combining special-purpose professional training, specialization training, and adaptation training. Special-purpose professional training, which focuses on the development of qualifications, is based on the requirements of individual job positions in construction companies. It includes both the hard and soft skills needed to do the job (Kagan, 2020; Tsalikova \& Pakhotina, 2019). Specialization training is designed to help workers acquire special knowledge and skills in connection with new technical and technological innovations, as well as changes in the content of job positions. It offers a means of developing an interdisciplinary approach in professional education. Despite the importance of both special-purpose and specialized education, however, the respondents' opinions indicate that the focus of education is on adaptation education and training, which does not create adequate conditions for the qualified further education of employees in the construction industry.

Under the current conditions of companies in the construction sector, the application of classical full-time education encounters considerable limitations, despite the fact that direct contact between learner and lecturer is still considered the best form of education. The problem of full-time education in construction companies is that participants would be required to interrupt their work activities. Thus, self-study comes to the fore, in the form of individual training as well as distance education, which allow fora guided form of education and are conducted either offline or online. For further education, where the learner pursues independent study and combines home study with consultations with a lecturer, the offline version is advantageous. Here, learners need not be connected to another computer via a network. Study materials are distributed online or by means of external storage media.

At present, the preferred form of e-learning is online education. The further development of online education has also been triggered by the current pandemic, during which distance education has come to be considered the more appropriate form of education. Online education can be implemented in two basic forms of communication: asynchronous and synchronous. Asynchronous online learning allows learners to study at the time that best suits them. Participants themselves choose the time they access educational materials.

Synchronous e-learning is based on the methods of full-time instruction. The lecturer/instructor controls the communication in the group and is able to selectively interact with one or more participants. Current information and communication technologies allow fora complete replacement of full-time education with synchronous online 
education. Online education is also possible in individual, group, and collective education. Education can be successfully adjusted to individual needs, i.e. tailored to the specific training participant. In the construction industry, it would be appropriate to apply participatory and cooperative forms of education.

\subsection{Interpretation of Statistical Verification}

The results of the statistical analysis of the first group of hypotheses in Table 6 were the basis for accepting the null hypothesis $1 \mathrm{Ho}$ and rejecting the alternative hypothesis $1 \mathrm{H} 1$. On the basis of the collected data, our first assumption was not confirmed, namely that in Slovakia's construction companies, men and women approach further education in different ways.

Based on the statistical analysis of the second group of hypotheses in Table 7 , we rejected the null hypothesis $2 \mathrm{Ho}$ and accepted the alternative hypothesis $2 \mathrm{H1}$, which means that the level of completed education of the respondents statistically significantly affects their approach to and interest in further education, which is expected to be reflected in a higher percentage using targeted information (A3) and the preference for further voluntary education (B3). This assumption was not borne out, as evidenced by Table 10, in which the summary indicators are evaluated as a percentage according to the level of completed education.

Table-10.Evaluation of approach and interest in further education by completed education

\begin{tabular}{l|c|c|c|c|c|c}
\hline \multirow{2}{*}{ Indicator/ Education } & \multicolumn{3}{|c}{ A } & \multicolumn{3}{c}{ B } \\
\cline { 2 - 7 } & $\mathbf{A 1}$ & $\mathbf{A 2}$ & $\mathbf{A 3}$ & $\mathbf{B 1}$ & $\mathbf{B 2}$ & $\mathbf{B 3}$ \\
\hline SecEdVL & $18.52 \%$ & $0.00 \%$ & $3.70 \%$ & $17.59 \%$ & $0.00 \%$ & $4.63 \%$ \\
\hline SecEd M & $22.22 \%$ & $2.78 \%$ & $21.30 \%$ & $15.79 \%$ & $0.00 \%$ & $30.56 \%$ \\
\hline Uni,1st level & $1.85 \%$ & $0.00 \%$ & $9.26 \%$ & $0.00 \%$ & $0.00 \%$ & $11.11 \%$ \\
\hline Uni, 2nd level & $8.33 \%$ & $0.00 \%$ & $12.04 \%$ & $0.93 \%$ & $0.00 \%$ & $19.44 \%$ \\
\hline Note: meaning of abbreviations $\%$ & \\
SecEdAC - secondary education - apprenticeship certificate \\
SecEd M - secondary education - graduation (GCSE) \\
Uni, 1st level - higher/university education \\
Uni, 2nd level - higher/university education.
\end{tabular}

The third group of hypotheses concerned the impact of the job position of people working in Slovakia's construction companies on their approach to further education. The statistical analysis of the results in Table 8 confirmed the statistical significance, that is to say, the job position of the respondents statistically significantly affects their approach to further education. Based on these results, we accepted hypothesis $3 \mathrm{H} 1$ and rejected hypothesis3Ho. At the same time, the assumption that managers are more interested in further education than nonmanagerial employees was corroborated, as demonstrated in Table 11.

Table-11. Evaluation of interest in further education by job position

\begin{tabular}{l|c|c|c|c|c|c}
\hline \multirow{2}{*}{ Indicator/ Job position } & \multicolumn{3}{|c}{ A } & \multicolumn{3}{c}{ B } \\
\cline { 2 - 7 } & $\mathbf{A 1}$ & $\mathbf{A 2}$ & $\mathbf{A 3}$ & $\mathbf{B 1}$ & $\mathbf{B 2}$ & $\mathbf{B 3}$ \\
\hline Self-employed & $29.63 \%$ & $1.85 \%$ & $7.41 \%$ & $28.70 \%$ & $0.00 \%$ & $10.19 \%$ \\
\hline Manager & $21.30 \%$ & $0.93 \%$ & $38.89 \%$ & $5.56 \%$ & $0.00 \%$ & $55.56 \%$ \\
\hline Source: prepared by authors.
\end{tabular}

Based on the results of the statistical analysis of the data pertaining to the fourth group of hypotheses, shown in Table 9, we rejected the null hypothesis $4 \mathrm{Ho}$ and accepted the alternative hypothesis $4 \mathrm{H} 1$. This means that the size of the company the employee works for has a statistically significant effect on their approach to further education. However, as in the case of the second group of hypotheses, in this case the assumption that large companies would have a greater interest in education than small and medium-sized companies have not been corroborated. This is evidenced by the values of indicators A3 and B3 demonstrated in Table 12.

Table-12. Evaluation of interest in further education by company size.

\begin{tabular}{l|c|c|c|c|c|c}
\hline \multirow{2}{*}{ Indicator/ Company size } & \multicolumn{3}{|c}{ A } & \multicolumn{3}{c}{ B } \\
\cline { 2 - 7 } & $\mathbf{A 1}$ & $\mathbf{A 2}$ & $\mathbf{A 3}$ & $\mathbf{B 1}$ & $\mathbf{B 2}$ & B3 \\
\hline Micro-company & $29.63 \%$ & $1.85 \%$ & $5.56 \%$ & $28.70 \%$ & $0.00 \%$ & $8.33 \%$ \\
\hline Small company & $20.37 \%$ & $0.00 \%$ & $18.52 \%$ & $5.56 \%$ & $0.00 \%$ & $33.33 \%$ \\
\hline Medium-sized company & $0.00 \%$ & $0.93 \%$ & $9.26 \%$ & $0.00 \%$ & $0.00 \%$ & $10.19 \%$ \\
\hline Large company & $0.93 \%$ & $0.00 \%$ & $12.96 \%$ & $0.00 \%$ & $0.00 \%$ & $13.89 \%$ \\
\hline
\end{tabular}

\subsection{Summary}

In conclusion, it can be stated that there are significant hurdles to further education in construction companies in Slovakia. The research conducted has identified approximately the same percentage of respondents who seek to assess their educational needs using commonly available data and special-purpose data. These data most frequently include information from employee appraisals, legislation, and internal controls. Most respondents only rarely use specific methods for acquiring special-purpose information; the most frequently used method is observation. In the context of the different kinds of education, it is particularly qualification education that is important to the construction industry. However, according to our findings, adaptation education and introductory training are the most frequently used in practice, which is inadequate in terms of the quality of further education. As for the forms of education, currently, e-education is preferred, either online or offline, but participative and cooperative forms of education are also recommended.

Based on the statistical analysis, differences in approaches to further education were confirmed based on respondents' education, job position, and company size. These factors can be considered fundamental to a differentiated approach to further education for separate target employee groups. 


\subsection{Limitations of the Study and Recommendations for Further Research}

The results of our study are limited by several factors: namely, the size of the research sample, in which there is a significant gender imbalance in the makeup of the respondent pool (which is however typical of the construction industry) and a high rate of subjectivity in the respondents' answers. These drawbacks may be eliminated by increasing the count (rate) of the research sample.

Since a different approach to further education was corroborated in the cases of different levels of education, job positions, and company sizes, in further research it may be desirable to focus separately on individual target employee groups.

Apart from that, in future research activities, it will be necessary to address special-purpose methods of acquiring information/data. These methods reveal not only the needs resulting from the existing gaps in employee education, but they also introduce the relationship between subjective employee assumptions about their work performance and the conditions that result from changes in work activities and increasing demands placed on employees.

To assess educational needs, it is essential to apply a positive approach to education, one that is responsive to suggestions and future requirements in its development of new materials, techniques and technologies, as well as the requirements placed on employees' knowledge and skills by other professional disciplines (Nuernberg, 2011).

The situation in modern society and the development of new information and communication technologies allow further professional education to be conducted in the form of distance education. In addition, various types of distance education may, to a considerable extent, also replace full-time education and provide employees with the kind of education that fully respects working conditions and facilitates the education and training of employees without interfering with operating modes and work organization.

\section{References}

Act No. 311. (2001). Coll., Code of Labour as amended. Bratislava, Slovak Republic: Publishing House Nová Práca.

Ahn, Y. H., Pearce, A. R., Wang, Y., \& Wang, G. (2012). Drivers and barriers of sustainable design and construction: The perception of green building experience. International Journal of Sustainable Building Technology and Urban Development, 4(1), 35-45. Available at: https://doi.org/10.1080/2093761X.2012.759887.

Armstrong, M. (2007). Human resource management. Prague: Grada Publishing.

Bartoňková, H. (2010). Corporate education. Strategic approach to employee training. Prague: Grada Publishing.

Beláňová, B. (2020). Human resources policy in relation to cybernetic security in slovak medium and small companies in current problems of the corporate sector 2020. Paper presented at the 17th International Scientific Conference, Paris: Édition Diffusion Presse Sciences.

Boroš, J. (2002). Introduction to psychology. Bratislava: IRIS.

Building Information Modeling- BIM. (2019). Sustainability and digitization in construction. Retrieved from: https://www.bimas.sk/singlepost/2019/10/21/udr\%C5\%BEate\%C4\%BEnos\%C5\%A 5-a-digitaliz\%C3\%A 1cia-v-stavebn\%C3\%ADctve.

Cahn, M. S. (2009). Philosophy of education: The essential texts. New York: Routledge.

Doyle, A. (2020a). How to prepare for a behavioral job interview, Retrieved from: https://www.thebalancecareers.com/behavioral-jobinterviews-2058575/ (Accessed 17 July 2020).

Doyle, A. (2020b). What are soft skills? Definition and examples of soft skills, Retrieved from: https://www.thebalancecareers.com/whatare-soft-skills-2060852 (Accessed 17 July 2020)

Dubcová, G., \& Foltínová, L. (2019). Model of the education for adults in slovakia. Paper presented at the In: Proceedings of 8th Teaching \& Education Conference, Vienna, 17 September 2019.

Dvořáková, Z. (2007). Human resources management. Prague: C. H. Beck.

Dvorakova, Z. (2012). Human resource management. Prague: C. H. Beck.

European Commission. (2019). Directorate-general for education, youth, sport and culture, key competences for lifelong learning, publications office of the EU. Themes: Education policy.

Eurostav. (2017). Forum of slovak construction industry, Retrieved from: www.eurostav.sk/sk/konferencie/odborna-konferencia-zspsforum-slovenskeho-stavebnictva/zakladne-informacie 12345678 (Accessed 21 September 2020).

Flešková, M., \& Dolinská, V. (2010). Applied psychology for economists and managers. Bratislava, Slovak Republic: Iura Edition.

Galajdová, V. (2007). Development of human resources. Zvolen: Publisher of the Trnava University, Zvolen.

Hanák, R. (2016). Data analysis for social sciences. Bratislava, Slovak Republic: Publisher EKONÓM.

Harper, M. (2021). Letter from the new commissioning editor - Martin Harper. Journal of Occupational and Environmental Hygiene, 18(1), D1 $-\mathrm{D} 1$.

Hroník, F. (2006). Employee evaluation. Prague: Grada Publishing.

Ibrahim, R., Boerhannoeddin, A., \& Bakare, K. K. (2017). The effect of soft skills and training methodology on employee performance. In: European Journal of Training and Development, 41(4), 388-406. Available at: https://doi.org/10.1 108/EJTD-08-2016-0066.

Joniaková, Z. (2016). Human resource management. Bratislava: Wolters Kluwer.

Kagan, J. (2020). Hard skills, the investopedia express podcast. Retrieved from: https://www.investopedia.com/terms/h/hard-skills.asp (Accessed 25 November 2020).

Karlovitz, J. T. (2013). Questions and perspectives in education. Komárno: International Research Institute.

Karlovitz, J. T. (2016). Studies from education and society. Komárno: International Research Institute, s.r.o.

Kocianová, R. (2010). Personnel activities and methods of personnel work. Prague: Grada Publishing.

Koubek, J. (2004). Work performance management. Prague: Management Press.

Koubek, J. (2015). Human resources management: Basics of modern human resources. Prague: Management Press.

Kubálková, M. (2017). Video recordings in education (486-493) hradec economic days. Paper presented at the Proceedings of the International Scientific Conference: January 31st and February 1st, 2017, Hradec Králové, Czech Republic [e-source]. Hradec Králové, Czech Republic: University of Hradec Králové.

Kubínyi, L., \& Veteška, J. (2017). Motivation and Barriers in further professional education of soldiers, (pp. 283-291), Adult Education 2016 - bases and inspiration for theory and practice. Paper presented at the Proceedings of the 6th International Adult Education Conference, 1314th December 2016 Prague. Prague: Czech Adult Education Society.

Lifelong Education. (2021). Ministry of education, science, research, and sport of the slovak republic, Retrieved from: https://www.minedu.sk/celozivotne-vzdelavanie/.

Liles, R. T., \& Mustian, R. D. (2004). Core competencies: A systems approach for training and organizational development in extension. The Journal of Agricultural Education and Extension, $10(2)$, 77-83.

Macková, Z. (2012). Psychology. Bratislava: Publisher Economist.

Matulčíková, M., \& Matulčík, J. (2019). Career and education management. Bratislava: Publisher Economist.

McCulloch, G., \& Crook, D. (2008). The routledge international encyclopedia of education. London: Routledge.

Mendíková, O. (2010). Teaching skills: Manual of a successful lecturer. Prague: City.

Mpofu, M., \& Hyathywayo, C. K. (2015). Training and development as a tool for improving basic service delivery; The case of a selected municipality. Journal of Economics, Finance and Administrative Science, 20(39), 133-136. Available at: https://doi.org/10.1016/ j.jefas.2015.10.004.

Mužík, J. (2011). Management of the educational process. Andragogical didactics. Prague: Wolters Kluwer. 
Nuernberg, E. (2011). The power of positive thinking. Prague: Grada Publishing.

Panitsides, E. A., \& Talbot, J. P. (2016). Lifelong learning: Concepts, benefits and challenges. Series: Education in a competitive and globalizing world (1 st ed.). New York: Nova Science.

Park, J. H., Lee, K. W., \& Dabelko-Schoeny, H. (2016). A comprehensive evaluation of a lifelong learning program: Program 60. The International Journal of Ageing and Human Development, 84(1), 88-106. Available at: https://doi.org/10.1177/0091415016668352.

Pauknerová, D. (2012). Psychology for economists and managers. Prague: Grada Publishing.

Pavlov, I., \& Neupauer, Z. (2019). Adult docility - the hidden potential in the era of artificial intelligence (25-35). Paper presented at the In: Proceedings of the 8th International Adult Education Conference 11-12 December 2018, Prague, Czech Republic, Adult Education 2018- Transformation in the Era of Digitization and Artificial Intelligence / Adult Education 2018 - Transformation in the Era of Digitization and Artificial Intelligence Editor Jaroslav Veteška, Praha / Prague 2019.

Pivovarová, D. (2017). Behavioral method of interview conducting - what to watch out for.

Porvazník, J., Ladová, J., \& Rajošová, V. (2007). Holistic management: Pillars of competence in management. Žilina: Slovak Republic: Publisher Poradca podnikatel'a.

Prusáková, V. (2001). Adult education in the scope of the place of municipalities. Bratislava: STIMUL.

Schoultz, M., Ohman, J., \& Quennerstedt, M. (2020). A review of research on the relationship between learning and health for older adults. International Journal of Lifelong Education, 39(5-6), 528-544. Available at: 10.1080/02601370.2020.1819905.

Schultze, R., \& Roberts, R. D. (2007). Emotional Intelligence. Prague: Portal.

Seho, H., \& Malošíková, S. (2018). Project learning by doing at FA ČVUT. Architecture and Urbanism, 52(3-4), $210-219$.

Slangal, R. (2018). Andragogická podstata vzdělávání vzdělávání / Andragogical basis of adult education. Paper presented at the In: Proceedings of the 7th International Adult Education Conference 11-12 November 2017, Prague, Czech Republic, Editor Jaroslav Veteška, Prague.

Stáfek, P., Sanova, P., Novotná, P., \& Laputková, A. (2016). Effectiveness of retraining as an instrument for solving the problem of structural unemployment in the Czech Republic. International Journal of Economics and Financial Issues, 6(3), 926-932.

Stuchlíková, I. (2007). Basics of psychology of emotions. Prague: Portal.

Suchý, J., \& Náhlovský, P. (2012). Positive emotions: How to strengthen and develop them in personal and professional life. Prague: Grada Publishing.

Szarková, M. (2009). Psychology for managers and entrepreneurs. Bratislava: Sprint Two.

Szarkova, M. (2013). Personnel marketing and personnel management. Bratislava: Publ. Economist.

The Oxford Handbook of Lifelong Learning. (2011). Edited by manuel (2nd ed.). London: Oxford University Press.

Tomczyk, Ł. (2018). Digital literacy and safety. Challenge for adult education and media pedagogy - results of research among teachers in uppersecondary schools in Poland. Paper presented at the Proceedings of the 7th International Adult Education Conference 'Adult Education 2017 - in times of resonant social changes', 11-12 November 2017, Prague, Czech Republic, Editor Jaroslav Veteška, Prague, 2018.

Tsalikova, I., \& Pakhotina, S. (2019). Scientific research on the issue of soft skills development (review of the data in international databases of scopus, web of science. The Education and Science Journal, 21(8), 187-207. Available at: 10.17853/1994-5639-2019-7-187-207.

Ullrich, D., Ambrozová, E., Koleňák, J., \& Pokorný, V. (2019). Possible pitfalls of education education for environment, society and industry 4.o / Possible pitfalls in adult education for the environment, society and Industry 4.0. Paper presented at the Proceedings of the 8th International Adult Education Conference 11-12 December 2018, Prague, Czech Republic, Vzdělávání adult 2018- transformation in the era of digitalization and artificial intelligence / Adult Education 2018 - Transformation in the Era of Digitization and Artificial Intelligence Editor Jaroslav Veteška, Prague / Prague 2019.

Urban, J. (2013). Educational needs analysis. Human Resources Management, 9(1), 50

Vaculík, M. (2010). Assessment center: Psychology in people selection and development. Brno: NC Publishing.

Veteška, J. (201 1). Transformations of school education in a biodromal context. Prague: Verlag Dashöfer, Publishing House.

Veteška, J., \& Kursch, M. (2018). Paradigm 'Education 4.0' in the era of digitization and globalization. Paper presented at the Proceedings of the 8th International Adult Education Conference 11-12 December 2018, Prague, Czech Republic, Adult Education 2018 Transformation in the Era of Digitization and Artificial Intelligence Editor Jaroslav Veteška, Praha/Prague 2019.

Vetrakova, M. (2011). Human resources and their management. Banská Bystrica: Matej Bel University, Faculty of Economics.

Vodák, J., \& Kucharčíková, A. (2007). Effective employee education. Prague: Grada Publishing.

Wagnerová, I. (2008). Performance evaluation and management. Prague: Grada Publishing

Walker, J. (2003). Modern personnel management: Latest trends and technologies. Prague: Grada Publishing.

Wilding, C. (2010). Emotional Intelligence. The influence of emotions on personal and professional success. Prague: Grada Publishing.

Wong, M. L., \& May. (1998). An evaluation on the employees' retraining programmes in Hong Kong. Employee Relations, 20(4), 404-414.

Zubr, V., Mohelská, H., \& Sokolová, M. (2017). Factors with positive and negative impact on learning organization, (980-984), Hradec Economic Days (2017). Paper presented at the Proceedings of the International Scientific Conference: January 31 st and February 1st, 2017, Hradec Králové, Czech Republic [e-source]. Hradec Králové, Czech Republic: University of Hradec Králové.

Zufan, J. (2012). Moderní personalistika ve službách. Prague: Wolters Kluwer. 